\title{
Position Statement by Experts of the Polish Menopause and Andropause Society on menopausal hormone therapy with an oral combination drug containing oestradiol $1 \mathrm{mg}$ and progesterone $100 \mathrm{mg}$
}

\author{
Małgorzata Bińkowska ${ }^{1}$, Grzegorz Jakiel ${ }^{1}$, Tomasz Paszkowski², Violetta Skrzypulec-Plinta ${ }^{3}$, \\ Wojciech Zgliczyński ${ }^{4}$ \\ 1 Department of Obstetrics and Gynecology, Centre of Postgraduate Medical Education in Warsaw, Poland \\ ${ }^{2}$ III Chair and Department of Gynecology, Medical University of Lublin, Poland \\ ${ }^{3}$ Chair of Women's Health, Medical University of Silesia in Katowice, Poland \\ ${ }^{4}$ Department of Endocrinology, Centre of Postgraduate Medical Education in Warsaw, Poland
}

At a meeting held on 20 May 2021, reviewed the available literature on the use of the medicinal product Bijuva® for the relief of menopausal symptoms.

Approximately a third of a contemporary woman's life is spent in the postmenopausal period. In most women, oestrogen deficiency causes symptoms which significantly impair their quality of life, and leads to a number of long-term health effects [1]. The most commonly used, generally recommended and most effective method of relieving the symptoms of menopause, especially vasomotor in nature, is menopausal hormone therapy (MHT) [2, 3].

For nearly twenty years, there has been a heated debate on the benefit-risk ratio of MHT, which was triggered by the publication of results of the Women's Health Initiative study in 2003 (6). It has now been established that the risk of adverse effects due to combined MHT, especially involving the mammary gland and the cardiovascular system, depends on the type of progestagen and the type and dose of oestrogen [4-7]. Multiple studies with high quality evidence indicate that from the point of view of the safety profile, the most beneficial form of combined MHT is $17 \beta$-oestradiol with micronised progesterone [3, 8-11]. This assumption laid the foundation for the concept of body-identical hormone replacement therapy which was proposed in 2014 by Nick Panay [12]. In this context, great hopes are being pinned on the first approved oral combination drug for MHT called Bijuva ${ }^{\circledR}$, containing a low dose of $17 \beta$-oestradiol and micronised progesterone. Both compounds, which are the active substances of this drug, are molecularly and chemically identical to the endogenous hormones oestradiol and progesterone [13].

The approval decision for Bijuva ${ }^{\circledR}$ was based on the results of a large phase 3 trial called REPLENISH. It was a prospective, randomised, double-blind, placebo-controlled, parallel group, multicenter trial with a follow-up period of 12 months. The trial assessed the safety and efficacy of softgel oral capsules containing $17 \beta$-oestradiol and micronised progesterone (E2/P4) in postmenopausal women aged 40-65 years with an intact uterus and moderate to severe vasomotor symptoms (VMS). In the REPLENISH trial, a total of 1,835 female subjects were randomised to one of four groups receiving combined E2/P4 products containing different doses of hormones (1 mg E2/100 mg P4, 0.5 mg E2/100 mg P4, 0.5 mg E2/50 $\mathrm{mg}$ P4, $0.25 \mathrm{mg}$ E2/50 mg P4) or placebo [14]. The results of the REPLENISH trial were presented in three key publications [14-16] and in approximately a dozen other papers containing post-hoc analyses of the trial's outcomes $[10,13,17-25]$ This study presents the conclusions of the REPLENISH trial regarding exclusively the subjects who were treated with the product approved as Bijuva ${ }^{\circledR}$, i.e. oestradiol $1 \mathrm{mg}+$ progesterone $100 \mathrm{mg}$ (E2/P4-1/100), focusing on the pharmacokinetic characteristics, clinical efficacy, and safety profile of the drug.

\section{Pharmacokinetic characteristics}

The pharmacokinetic parameters and bioavailability of orally administered oestradiol and progesterone in the REPLENISH trial were evaluated by Lobo et al. [23] and Pickar et al. [10]. The study found that the bioavailability of both $17 \beta$-oestradiol and progesterone contained in the E2/P4-1/100 product is similar to that determined in the reference single-ingredient products based on the same active substances. This proves that Bijuva 
successfully combines $17 \beta$-oestradiol and progesterone in a single oral formulation without significant losses in their bioavailability. Attempts to formulate such a drug, continuing for a number of years, were a technologically daunting task due to differences in the structure and solubility of the two hormones. The mean serum levels of $17 \beta$-oestradiol and progesterone during E2/P4-1/100 treatment were $38.1 \mathrm{pg} / \mathrm{ml}$ and $0.77 \mathrm{ng} / \mathrm{ml}$, respectively. The patients treated with E2/P4-1/100 achieved a stable phase of E2 and P4 concentrations after an average of 7 days of taking the drug $[10,23]$.

\section{Efficacy}

The co-primary efficacy endpoints in the REPLENISH trial included the frequency and severity of moderate to severe VMS after 4 and 12 weeks of E2/P4 treatment. Treatment with the product containing $1 \mathrm{mg}$ of E2 and $100 \mathrm{mg}$ of P4 was found to be significantly more effective than the placebo with respect to all endpoints related to VMS. A significant improvement in the frequency and severity of VMS was observed already in the third week of therapy, and the beneficial effect of E2/P4-1/100 on both the frequency and severity of these symptoms was gradually increasing until week 12 of patient follow-up [13, 14]. A significantly higher efficacy of E2/P4-1/100 compared with the placebo was also found in a study where the criteria for satisfactory clinical response included a reduction in the number of hot flush episodes by at least $50 \%$, complete elimination of severe hot flushes, and the number of vasomotor symptom-free days [20].

Another goal of the REPLENISH trial was to determine the level of clinical significance of the improvement in VMS observed in patients taking E2/P4-1/100. To this end, the Clinical Global Impression (CGI) rating scale was used. At 4, 8 and 12 weeks of therapy, the patients assessed the degree of improvement in their well-being on a 7-point Likert scale. The study showed that, according to patients treated with E2/P4-1/100, the decrease in the severity of VMS was clinically significant during the 12-week follow-up [19].

One of the primary endpoints of the REPLENISH study was the assessment of the effect of E2/P4-1/100 therapy on the quality of life of patients with VMS of at least moderate severity. The assessment was performed using the validated Menopause-Specific Quality of Life (MENQOL) questionnaire. A significant improvement was found in the quality of life of women taking E2/P4-1/100 for 12 weeks compared with the placebo, and the effect was sustained over the 12-month follow-up period [16].

Another aspect evaluated in the REPLENISH trial was the impact of E2/P4-1/100 therapy on sleep quality measured using the Medical Outcomes Study - Sleep Scale Questionnaire [15, 24]. At 12-month follow-up, there was a significant improvement in sleep quality in patients receiving E2/P4-1/100, which appears to be due both to a decrease in the severity of VMS induced by oestradiol and an effect of progesterone on sleep quality via GABAergic receptors [15].

\section{Safety profile}

Assessment of the endometrial safety profile was a primary endpoint of the REPLENISH trial $[14,25]$. The study included a total of 280 female patients receiving E2/P4-1/100 who underwent endometrial biopsy at baseline and after 12 months of treatment. An effective level of endometrial protection during E2/P4-1/100 therapy was demonstrated. The percentage of patients with histopathological features of endometrial hyperplasia after one year was only $0.36 \%$. Premature trial discontinuations due to abnormal uterine bleeding/ spotting were very rare, affecting just $1.4 \%$ of the trial subjects. The percentage of patients with no uterine bleeding increased with the duration of treatment, reaching $73 \%$ after one year of therapy. The US Food and Drug Administration recommends that the incidence rate for endometrial hyperplasia in MHT studies should not exceed 1\% after 12 months of drug use and be similar to that observed in the untreated population [26]. The results of the REPLENISH trial show that E2/P4-1/100-based therapy meets this criterion, so 100 $\mathrm{mg}$ of $\mathrm{P} 4$ used in a continuous regimen is an effective dose to balance the proliferative effect of $1 \mathrm{mg}$ of E2 on the endometrium [13].

The clinical data collected in the REPLENISH study were also analysed to determine the effects of 12-month E2/P4-1/100 treatment on body weight and blood pressure. The analysis revealed no clinically significant changes in these parameters among the women who were treated with the study product $[17,18]$.

Long-term treatment with the E2/P4-1/100 product was not found to be associated with any clinically significant changes in the blood lipid profile or fasting blood glucose levels $[4,17]$.

During 12-month E2/P4-1/100 therapy, there were no clinically significant differences in blood coagulation parameters such as antithrombin activity, protein S level, partial thromboplastin activation time, prothrombin time, fibrinogen concentration, and prothrombin index [14].

During one-year follow-up of patients treated with E2/P4-1/100, no cardiovascular adverse events were observed that could have a causal relationship with the therapy $[4,17]$.

Based on mammographic findings, the safety of 12-month therapy with E2/P4-1/100 for the mammary glands was evaluated [21]. For the purpose of the study, a total of 415 female patients treated with a product containing oestradiol $1 \mathrm{mg}$ and progesterone $100 \mathrm{mg}$ were enrolled. After 12 months of therapy, 3.7\% of 
these patients had abnormal mammography results (BI-RADS 3 or 4). In the placebo group, the proportion was $3.1 \%$. The difference was not statistically significant. In the group treated with E2/P4-1/100, breast cancer was diagnosed in two cases $(0.5 \%)$. The proportion does not differ from that observed among women receiving placebo in large studies such as WHI (0.33\%) [27] or PEPI (0.6\%) [11]. The population prevalence of breast cancer in women aged 40 to 64 years is $0.3 \%$ [28]. The results of the REPLENISH trial are consistent with the findings of previously published studies [9, 29] indicating that MHT based on oestradiol and progesterone does not increase the risk of breast cancer. Breast tenderness during therapy with E2/P4-1/100 was reported by $10.8 \%$ of patients, but only in $1.4 \%$ of cases it led to the discontinuation of therapy [21].

A total of $72 \%$ of subjects reported at least one adverse effect during their treatment with E2/P4-1/100, while in the placebo group the corresponding proportion was $52 \%$. The majority (75\%) of the adverse effects were mild. Adverse events classified as severe were reported in $6.3 \%$ of patients taking E2/P4-1/100 and in $2.6 \%$ of patients receiving placebo. A total of $11 \%$ of subjects discontinued their E2/P4-1/100 therapy because of adverse effects. For comparison, $6.6 \%$ of placebo subjects withdrew from the trial on account of adverse effects $[13,14]$.

In conclusion, the review of the REPLENISH trial results concerning the medicinal product $B i j u v a{ }^{\circledR}$, showed that the drug is effective in reducing menopausal vasomotor symptoms, has a positive effect on the quality of sleep, and improves the quality of life of patients. Based on the available study findings, the safety profile of the drug is favourable.

\section{Disclosure}

The authors report no conflicts of interest.

\section{References}

1. Baber RJ, Panay N, Fenton A. IMS recommendations on women's midlife health and menopause hormone therapy. Climacteric 2016; 19: 109. 150.

2. Paszkowski T, Bińkowska M, Dębski R, et al. Menopausal hormone therapy in questions and answers - a manual for physicians of various specialties. Menopause Rev 2019; 18: 1-8.

3. Stevenson JC, Rozenberg S, Maffei S, et al. Progestogens as a component of menopausal hormone therapy: the right molecule makes the difference. Drug Cont 2020; 9: 1-12.

4. Cobin RH, Goodman NF. AACE Reproductive Endocrinology Scientific Committee. American Association of Clinical Endocrinologists and American College of Endocrinology position statement on menopause 2017 update. Endocr Pract 2017; 23: 869-880.

5. Hamoda H, Panay N, Pedder H. The British Menopause Society \& Women's Health Concern 2020 recommendations on hormone replacement therapy in menopausal women. Post Reprod Health 2020; 26: 181-209.

6. Lee SR, Cho MK, Cho YJ. The 2020 Menopausal Hormone Therapy Guidelines. J Menop Med 2020; 26: 69-98.
7. The 2017 hormone therapy position statement of The North American Menopause Society. Menopause 2017; 24: 728-753.

8. Canonico M, Fournier A, Carcaillon L, et al. Postmenopausal hormone therapy and risk of idiopathic venous thromboembolism results from the e3n cohort study. Arterioscler Thromb Vasc Biol 2010, 13, 340-345.

9. Cordina-Duverger E, Truong T, Anger A, et al. Risk of breast cancer by type of menopausal hormone therapy: a case-control study among postmenopausal women in France. PLoS One 2013; 8: e78016.

10. Pickar JH, Bon C, Amadio JM, et al. Pharmacokinetics of the first combination 17b-estradiol/progesterone capsule in clinical development for menopausal hormone therapy. Menopause 2015; 22: 1308-1316.

11. Writing Group for the PEPI Trial. Effects of estrogen or estrogen/ progestin regimens on heart disease risk factors in postmenopausal women. the postmenopausal estrogen/progestin interventions (PEPI) trial. JAMA 1995; 273: 199-208.

12. Panay N. Body identical hormone replacement. Post Reprod Health 2014; 20: 69-72.

13. Archer DF, Bernick BA, Mirkin S. A combined, bioidentical, oral, $17 \beta$-estradiol and progesterone capsule for the treatment of moderate to severe vasomotor symptoms due to menopause. Expert Rev Clin Pharmacol 2019; 12: 729-739.

14. Lobo RA, Liu J, Kaunitz AM, et al. Effects of single-capsule 17ßestradiol/ progesterone (TX-001HR) on metabolic parameters and cardiovascular outcomes in menopausal women of the REPLENISH trial. Menopause 2018; 25: 1484-1485.

15. Kagan R, Constantine G, Kaunitz AM, et al. Improvement in sleep outcomes with a 17b-estradiol-progesterone oral capsule (TX-001HR) for postmenopausal women. Menopause 2019; 26: 622-628.

16. Simon JA, Kaunitz AM, Kroll R, et al. Oral 17b-estradiol/progesterone (TX-001HR) and quality of life in postmenopausal women with vasomotor symptoms. Menopause 2018; 26: 506-512.

17. Archer DF, Pickar JH, Graham S, et al. Effects of single-capsule 17 $\beta$ - estradiol/progesterone (TX-001HR) on weight and blood pressure in menopausal women of the REPLENISH trial. Menopause 2018; 25: 1496-1497.

18. Black DR, Minkin MJ, Graham S, et al. Effects of combined 17b-estradiol and progesterone on weight and blood pressure in postmenopausal women of the REPLENISH trial. Menopause 2020; 28: 32-39.

19. Constantine GD, Simon JA, Kaunitz AM, et al. TX-001HR is associated with a clinically meaningful effect on severity of moderate to severe vasomotor symptoms in the REPLENISH trial. Menopause 2020; 27: 1-6.

20. Kaunitz AM, Bitner D, Constantine GD, et al. 17b-estradiol/progesterone in a single, oral, softgel capsule (TX-001HR) significantly increased the number of vasomotor symptom-free days in the REPLENISH trial. Menopause 2020; 27: 1382-1387.

21. Liu JH, Black DR, Lisa Larkin L, et al. Breast effects of oral, combined 17bestradiol, and progesterone capsules in menopausal women: a randomized controlled trial. Menopause 2020; 27: 1388-1395.

22. Lobo RA, Archer DF, Kagan R, et al. A 17 $\beta$-estradiol-progesterone oral capsule for vasomotor symptoms in postmenopausal women: a randomized controlled trial. Obstet Gynecol 2018; 132: 161-170.

23. Lobo RA, Liu J, Stanczyk FZ, et al. Estradiol and progesterone bioavailability for moderate to severe vasomotor symptom treatment and endometrial protection with the continuous-combined regimen of TX001HR (oral estradiol and progesterone capsules). Menopause 2019; 26: 720-727.

24. Mirkin S, Graham S, Revicki DA, et al. Relationship between vasomotor symptom improvements and quality of life and sleep outcomes in menopausal women treated with oral, combined 17b-estradiol/progesterone. Menopause 2019; 26: 637-642.

25. Mirkin S, Goldstein SR, Archer DF, et al. Endometrial safety and bleeding profile of a 17b-estradiol/ progesterone oral softgel capsule (TX001HR). Menopause 2020; 27: 410-417.

26. https://www.fda.gov/media/75802/download

27. Chlebowski RT, Hendrix SL, Langer RD, et al. Influence of estrogen plus progestin on breast cancer and mammography in healthy postmenopausal women: the women's health initiative randomized trial. JAMA 2003; 289: 3243-3253.

28. National Cancer Institute. SEER Cancer Statistics Review 1975-2016; cancer of the female breast. https://seer.cancer.gov/csr/1975 2016/results_merged/sect_04_breast.pdf

29. Piette PCM. The pharmacodynamics and safety of progesterone. Best Pract Res Clin Obstet Gynaecol 2020; 69: 13-29. 